\title{
Experimental and numerical investigation of laboratory scale sheet pipe- typed automatic subsurface irrigation
}

\author{
Satyanto Krido Saptomo ${ }^{\mathrm{a}, *}$,Rudiyanto ${ }^{\mathrm{b}}$, Muhamad Askaric, Chusnul Arif ${ }^{\mathrm{a}}$, Willy Bayuardi \\ Suwarno $^{\mathrm{d}}$, Adlan $^{\mathrm{a}}$, Rusianto ${ }^{\mathrm{e}}$, Budi Indra Setiawan ${ }^{\mathrm{a}}$, Koremasa Tamura ${ }^{\mathrm{f}}$, Hiroshi Matsuda ${ }^{\mathrm{g}}$ \\ ${ }^{a}$ Department of Civil and Environmental Engineering, Bogor Agricultural University, Bogor 16680, Indonesia \\ ${ }^{b}$ Program of Crop Science, Faculty of Fisheries and Food Science, Universiti Malaysia Terengganu, Kuala Nerus 21030, Malaysia \\ ${ }^{c}$ Departement of Civil Engineering, Universitas Muhammadiyah Yogyakarta 55183, Indonesia \\ ${ }^{d}$ Department of Agronomy and Horticulture, Bogor Agricultural University, Bogor 16880, Indonesia \\ ${ }^{e}$ Meteo Nusantara Instrumen, Bogor 16620, Indonesia \\ ${ }^{f}$ Kyowa Kensetsu Kogyo Co., Ltd, Hagi 758-0061, Yamaguchi \\ ${ }^{g}$ Graduate School of Science and Engineering Systems Design, Yamaguchi University, Ube 755-8611, Japan
}

Article history:

Received: 16 November 2021 / Received in revised form: 24 December 2021 / Accepted: 26 December 2021

\begin{abstract}
Sheet pipe is a type of perforated pipe used for drainage designed initially for drainage but has the potential for sub-surface irrigation. The objectives of this study were to experiment and observe the performance of the sub-surface irrigation control system with sheet pipe. This investigation covered the observation of water table control and its effect on soil moisture. The detailed process of water flow during the setting of the water table was numerically modeled in 2 dimensions to observe the distribution of soil moisture, soil pressure, and flux. The results showed that the system successfully controlled the water table at the desired level in the experiment. The developed two-dimensional numerical simulation showed the distribution of soil moisture in the model center as a response to the water table increase, represented by the variable head. The soil wetting advances toward soil surface driven by the water table, which was increased gradually and reached saturation at the height of water table setpoint
\end{abstract}

Keywords: sheet-pipe; land water management; automation; internet of things; water table

\section{Introduction}

Sheet pipe is a type of perforated pipe used for drainage with mole drain. Its installation does not require the excavation of the line, but it can be carried out using a mole plow pulled by agricultural machinery to make a mole drain and, at the same time, to pull the sheet pipe. Sheet-pipe has an original form in a long sheet and is formed into a pipe using a sheet piper device. Sheet-pipe installations are usually at a depth of $30-50 \mathrm{~cm}$ from the soil surface and have the original function to assist land drainage.

In rice fields, the sheet-pipe installation significantly affects the soil's physical, hydraulics, and chemical properties. Some of the positive impacts on soil properties that determine the improvement of rice fields installed by perforated sheet pipes are soil bulk density, organic content, permeability, and airfield capacity [1]. Significant improvement in soil organic matter occurs due to the sheet-pipe installation, which contributes to increased soil porosity, air-filled capacity, and lower soil bulk density

In Indonesia, sheet-pipe was introduced in 2018 with feasibility study and field and laboratory research activities.

\footnotetext{
* Corresponding author.
}

Email: saptomo@apps.ipb.ac.id

https://doi.org/10.21924/cst.6.2.2021.604
The test in the laboratory showed that sheet-pipe is quite effective for having a drainage capacity higher than other drainage pipes type used in the experiment [2]. The drainage effect was also evidenced by observing water content and matrix potential in sheet pipe installations in Indonesia. Rice fields with sheet pipe installation can be drained more quickly than those without using sheet pipes. As soon as rain occurs, the water is immediately infiltrated at a parabolic rate up to 0.94 $\mathrm{cm} / \mathrm{h}$, higher than the standard steady-state infiltration rate of $0.121 \mathrm{~cm} / \mathrm{h}$, to facilitate its management to provide aerobic and anaerobic conditions [3].

Research showed that land with sheet pipe could increase the production up to $13 \%$ in a single trial of one rice planting season [4] although evapotranspiration was lower because the water level was maintained below the surface. For one year with rice-paddy-soybean and rice-paddy-paddy cropping patterns, the yield increased by $11.54 \%$ and $26.94 \%$ [5], respectively. On the same land, it was also observed that the water storage function of sheet pipe in comparison to the drainage function became more dominant in the dry season. This was presumably because in Sukamandi field station surface water was relatively abundant. These facts show the potential use of sheet-pipe as an irrigation system and subsurface drainage.

Swampland in Indonesia is accounted for 43.7 million hectares, with about 9.8 million hectares that are potential for 
agriculture [6]. In general, the paddy fields in tidal areas are inundated due to the high intensity of rainfall and sea tide [7]. In Indonesia, the average land productivity is about $3 \mathrm{t} / \mathrm{ha}$ of the wet paddy and can increase up to more than $5 \mathrm{t} / \mathrm{ha}$ with better water management, according to statistics 2011-2015 [8]. The reports on productivities of the swamplands paddy fields can also be found in $[9,10]$.

Reclaimed tidal lowland requires efforts to improve their suitability for rice cultivation, including drainage systems and water barriers to retain the water in the cultivated land [11]. Water management at tidal lowland should avoid excessive drainage causing land drying and pyrite layer oxidation. The critical value of water table is achieved at $60 \mathrm{~cm}$ level where soil water content at the root zone is at permanent wilting point. INthe water table at the depth of $10-20 \mathrm{~cm}$, the soil surface is in saturation. When it is dropped to $30-40 \mathrm{~cm}$, the soil approaches field capacity. The variation of water table at 20-30 $\mathrm{cm}$ shows that the land is suitable for rice crop, and the one at $40-50 \mathrm{~cm}$ would be suitable for second crops such as corn [12], [13].

Designing a subsurface irrigation system is not simple because the water infiltration area is invisible. Variations in the water table profile depend on the distance from the subsurface irrigation pipe. They may cause crops to grow unevenly, for instance, for vegetables such as spinach [14-17]. Therefore, it is necessary to design soil moisture and soil potential to be maintained at optimal conditions by providing adequate water beneath the surface. Water conditions (soil moisture and soil potential) in the soil can be simulated by HYDRUS, which simulates the water movement in the soil to check irrigation system [17-20].

Several previous studies confirmed the model's suitability for simulating water movement during subsurface irrigation. A comparison of HYDRUS-simulated water contents for a subsurface line-source drip irrigation with observed field data for three different emitter discharge rates is presented by [21]. The model was also used to evaluate laboratory and field data involving water movement in clay loam from point water sources buried at different depths and with different discharge rates [22] and validated for the simulation of water movement from a subsurface drip irrigation in several field experiments [23]. An experimental and numerical approach in the evaluation distribution of moisture using a ring-shaped subirrigation emitter was also presented [24]. More details about HYDRUS can be found in $[25,26]$.

The automation of sub-surface irrigation and drainage using sheet-pipe technology concept was presented [27] to answer the need for proper technology for increasing the yields of the type of land where water management was challenging. The aim was to control the water table with either drainage or irrigation, thus enabling multi-product cultivation that requires different water conditions and increasing the land's productivity. However, a detailed study of sheet-pipe subsurface irrigation has not been performed outside Japan, where it was first developed. Thus, developing this technology is challenging.

A laboratory-scale model of an automatic sheet-pipe subsurface irrigation system with internet connectivity was developed. The observations on preliminary experiments were presented in [28], showing the level of success in maintaining the water table. Comparing the number of successes, undershoot (below than lower setpoint), and overshoot (over the upper setpoint) to the number of events and the percentage of success, overshoot and undershoot were obtained. They were $86 \%, 9 \%, 5 \%$ of the total event. Furthermore, an analysis of the actual water table error, the deviation against the setpoint water level, was carried out and showed the RMSE of $2.6 \mathrm{~cm}$.
The system had been improved but required further investigation of its performance before being applied at the sheet-pipe field, including the irrigation control mechanism and its effect on the distribution and availability of water in the soil. The objectives of this study were to experiment and observe the performance of the subsurface irrigation control system with sheet pipe. This investigation covered the observation of water table control and its effect on soil moisture and soil potential with an experimental laboratory and numerical model.

\section{Materials and Methods}

\subsection{Experimental model}

The experimental model was made as a miniature rice field with sheet pipe typed, perforated pipes for subsurface drainage installation. This setting was prepared to enable the land for various cultivation practices that required saturated or flooded conditions and for plants that required good soil aeration. The dimension of the model was $200 \mathrm{~cm} \times 200 \mathrm{~cm}$ in area, with a soil thickness of $40 \mathrm{~cm}$. Two sheet pipes were installed at a depth of $20 \mathrm{~cm}$ from the surface installed in parallel with a distance of 1 $\mathrm{m}$. However, because of the model size, this distance was only $1 / 4$ of the standard distance of installation in the field, and it was not possible to apply the actual distance.

The soil used in this experimental model was an artificial media of soil mixture of mineral soil and organic matter and has been used in one rice-growing season. Soil texture consisted of sand, silt, and clay, respectively $8 \%, 19 \%$, and $73 \%$, with organic matter content of $17 \%$. The bulk density of the soil media was $0.87 \mathrm{gr} \mathrm{cm}^{-3}$ with a total pore space of 0.60 and a permeability $(\mathrm{Ks})$ of $5 \mathrm{~cm} / \mathrm{hr}$. Soil water content at $\mathrm{pF} 1$, 2, 2.54 and 4.2 in $\mathrm{cm}^{3} \mathrm{~cm}^{-3}$ was $0.40,0.34,2.4$ and 14.36, respectively.

The irrigation system applied in this experimental model used a sheet pipe installed near the base (Fig. 1). The pipe had a vertical distance of $5 \mathrm{~cm}$ from the soil base to control the water table. At the field, sheet pipe was installed inside mole drain, a tunnel in the soil as underground drain lines to prevent the soil from collapsing and completely buried the sheet pipe. Mole drain had a surrounding wall of compacted soil formed during land preparation with machinery. This mole drain's wall was watertight as long as the structure was maintained, and for simplification, PVC pipes with a diameter of 4 inches represented a $10 \mathrm{~cm}$ diameter mole drain.

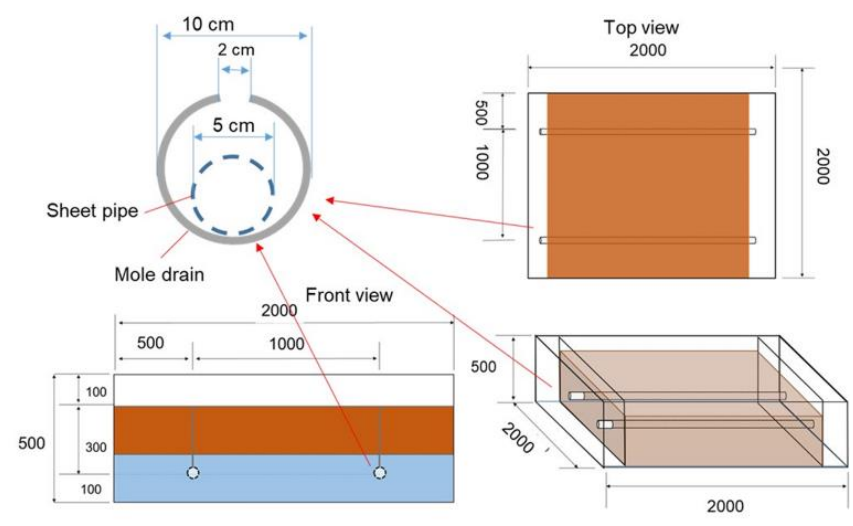

Fig. 1 Experimental model of subsurface drainage

A mole drain had a fissure up to the soil surface, induced by machinery during machinery plows, increasing drainage 
performance [29]. Therefore, the pipe was also prepared with an opening at its top as a water entrance. Water then entered through the pores of the sheet pipe and flowed to the drain. On the other hand, when the water has flowed into the sheet pipe for irrigation, the water flowed out from sheet pipe through the pores and filled the 'mole drain' pipe in the field. The water continued to flow driven by the difference in pressure head in the reservoir and the soil. Thus, in the irrigation process, the water did not come out directly through the sheet pipe pores to the soil but through the opening above the pipe after the pipes were full.

The scheme of the water management setting are as shown in Fig. 2. Water was supplied through a connected reservoir connected with the experimental model's sheet pipe. By setting up the water level in the reservoir, it was expected that the water table in the soil followed the water level in the reservoir. In this experimental setting, water only came out through the evaporation and drainage processes set at ground level to avoid inundation. In addition, a plastic sheet roof covered the box to avoid any rainfall effect on the soil.

\section{Rainfal}

\section{$\downarrow \downarrow \downarrow \downarrow \downarrow$}

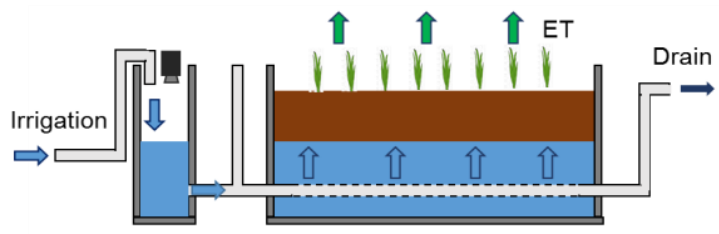

Fig. 2 Sub-surface irrigation setting

An automatic irrigation model was developed to set the water table by controlling the water flow through sheet-pipe below the ground surface. Water was fed through a reservoir using a solenoid valve with a working voltage of 12 volts, with a pipe diameter of 0.75 inches, controlled automatically. The specified water table height was called as the setpoints. In this case, the water table was set in a range between a maximum (upper setpoint) and minimum (lower setpoint) to avoid rapid changes in the on-off status of the solenoid valve that could cause damage. The control system irrigated when the water table was below the lower setpoint by opening the solenoid valve and raising the water table. After a while of irrigation, as the water table reached a higher level than the upper setpoint, the system closed the solenoid valve, and the water flow stopped. The water level was monitored continuously using a water level sensor placed in the reservoir.

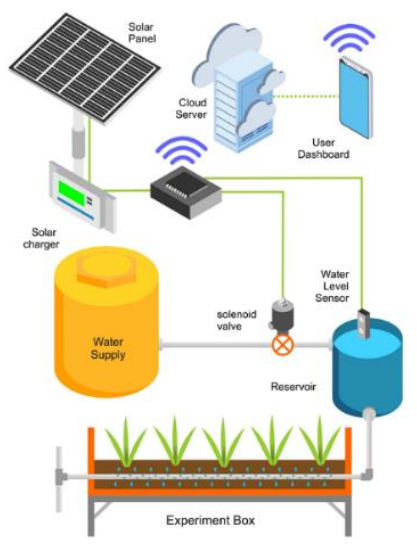

Fig. 3 Scheme (based on [28]) of experimental subsurface irrigation automation

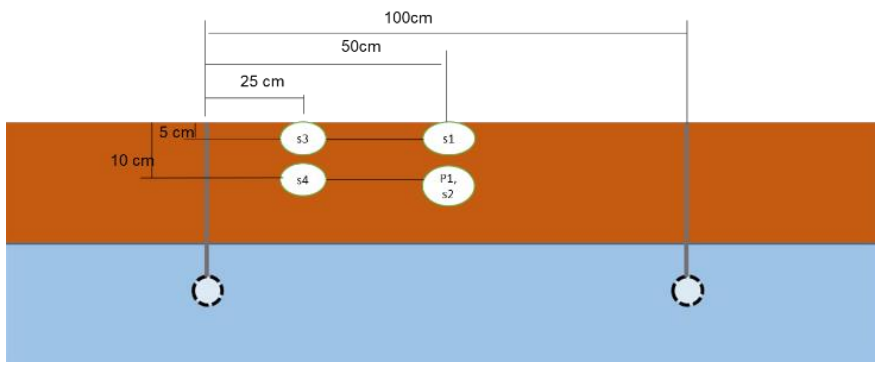

Fig. 4 Soil moisture observation, s: soil moisture, P: pressure

An irrigation control system has been developed using a programmable digital controller and wireless internet communication function. The developed program includes measurement, automatic irrigation control, local data storage, internet connection, data transmission to the server, and retrieval of setting data from the server. Users can access the server via a web browser with a dashboard that features tabular data and graphical display, data downloads, and changes of settings that will be used by the control system, especially regarding the setpoints. Therefore, the setting of the water table and the observation of irrigation control performance can be done by telemetry with the support of the Internet of things (IoT) system. The experimental automatic subsurface irrigation system pictures and schematics are as shown in Fig. 3.

Observations were carried out using a soil moisture sensor at two soil depths to obtain the more detailed figures of the vertical distribution of soil moisture at a certain distance from the sheet pipe. The sensors were placed to observe the average moisture at a depth of $0-5 \mathrm{~cm}$ and $10-15 \mathrm{~cm}$, with a lateral distance of $50 \mathrm{~cm}$ and $25 \mathrm{~cm}$ from the sheet-pipe line, as depicted in Fig. 4.

\subsection{Numerical investigation}

Water flow in a variably saturated medium was described using the Richard equation. The Richard equation for 2D vertical isotropic soil with positive vertical upward is expressed by

$$
\begin{gathered}
\frac{\partial \theta}{\partial t}=\frac{\partial}{\partial z}\left[K(h) \frac{\partial h}{\partial z}+K(h)\right]+\frac{\partial}{\partial x}\left[K(h) \frac{\partial h}{\partial x}\right]-S(z, x, t) \\
\frac{\partial \theta}{\partial t}=\frac{\partial}{\partial z}\left[K(h) \frac{\partial h}{\partial z}+K(h)\right]+\frac{\partial}{\partial x}\left[K(h) \frac{\partial h}{\partial x}\right]-S(z, x, t)
\end{gathered}
$$

where $\theta$ is the volumetric soil water content $\left[\mathrm{L}^{3} \mathrm{~L}^{-3}\right]$, $\mathrm{t}$ is the time $[\mathrm{T}], \mathrm{h}$ is the pressure head $[\mathrm{L}], \mathrm{z}$ and $\mathrm{x}$ are the vertical and horizontal and space coordinates [L], respectively, $\mathrm{K}$ is the unsaturated hydraulic conductivity $\left[\mathrm{L} \mathrm{T}^{-1}\right]$, and finally, $\mathrm{S}(\mathrm{z}, \mathrm{x}$, t) is a sink term $\left[\mathrm{L} \mathrm{T}^{-1}\right]$ such as the rate of root water uptake. Hydrus is a model [30] that implements Galerkin finite element method and is based on iterative mass conservation used to solve Eq. (1).

The closed-form functions of the Mualem-van Genuchten model $([31 ; 32])$ was used to describe soil water retention and unsaturated hydraulic conductivity, given as follows:

$$
\begin{aligned}
& \theta(h)=\left(\theta_{s}-\theta_{r}\right) S_{e}(h)+\theta_{r} \\
& \theta(h)=\left(\theta_{s}-\theta_{r}\right) S_{e}(h)+\theta_{r} \\
& S_{e}(h)=\left(1+|\alpha h|^{n}\right)^{-m} \quad S_{e}(h)=\left(1+|\alpha h|^{n}\right)^{-m}
\end{aligned}
$$




$$
\begin{gathered}
K(h)=K_{s} S_{e}{ }^{L}\left[1-\left(1-\mathrm{S}_{e} \frac{1}{m}\right)^{m}\right]^{2} \\
K(h)=K_{s} S_{e}{ }^{L}\left[1-\left(1-\mathrm{S}_{e}{ }^{\frac{1}{m}}\right)^{m}\right]^{2}
\end{gathered}
$$

where $\theta_{\mathrm{s}}$ is the saturated water content $\left[\mathrm{L}^{3} \mathrm{~L}^{-3}\right], \theta_{\mathrm{r}}$ is the residual water content $\left[\mathrm{L}^{3} \mathrm{~L}^{-3}\right], \mathrm{Se}$ is the adequate saturation $[-], \alpha\left[\mathrm{L}^{-1}\right]$, $\mathrm{n}[-]$, and $m=1-1 / \mathrm{n}[-]$ are shape parameters, $\mathrm{K}_{\mathrm{s}}$ is the saturated hydraulic conductivity $\left[\mathrm{L} \mathrm{T}^{-1}\right]$, and $\mathrm{L}$ is a parameter that accounts for the tortuosity and connectivity of the flow system [-]. Soil water retention parameters can be optimized using Solver add-in Excel by fitting the soil physical and hydraulic properties data from laboratory analysis.

In this study, the HYDRUS (2D/3D) model [25], mentioned as HYDRUS, was used to simulate soil water movement during subsurface irrigation with a sheet pipe. HYDRUS was used to simulate and estimate soil water and moisture distribution, which could not be sufficiently observed using a sensor. The soil in the experimental model was assumed to be uniform in the $y$-direction so that cross-sections could represent it in the $\mathrm{x}$ and $\mathrm{z}$ directions as in the lower left in Fig. 5. The soil thickness was set to $40 \mathrm{~cm}$ with a $10 \mathrm{~cm}$ diameter pipe planted $5 \mathrm{~cm}$ from the base; a fissure was opened at the top of the pipe. Sheet pipe was placed inside the pipe; however, because the pipe was impermeable, water could only escape through the opening in the top of the pipe after the pipe was filled with water. The hydraulic head of water flowed out from this point dependent on the head of inlet water; therefore, a defined head might be applied as the boundary condition.

The boundary at the pipe's opening was determined as a variable head, equal to the water level in the reservoir that supplies the water. As the pipe's opening had height $Z=15 \mathrm{~cm}$ from soil base, $0 \mathrm{~cm}$ head at the point was equal to $15 \mathrm{~cm}$. The atmospheric boundary was set at the top face of the soil. Noflux boundary was set at the soil's left, right, and bottom face; and the wall of mole-drain pipe except the top (Fig. 5).
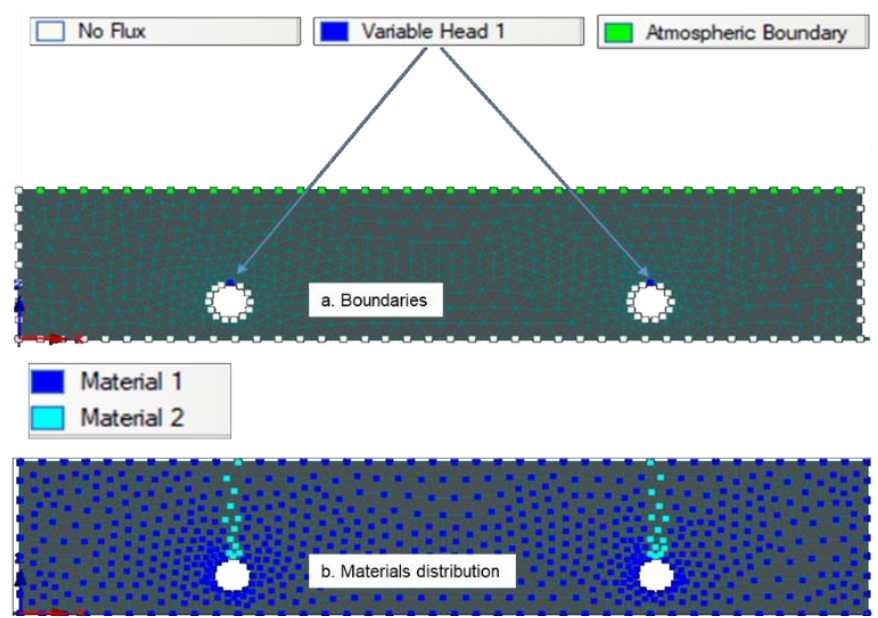

Fig. 5 Experimental model of subsurface drainage a) Boundary conditions; b) Material set up in numerical model; Material 1 is the prepared soil media in the experimental box, material 2 is sand with higher Ks. The soil parameters of Materials 1 and 2 are presented in table 1

Like mole drain at the field, there was a fissure above the pipe for drainage waterways in this experimental model. Consequently, if the fissure walls were stable, then the modeling could be carried out as if there was a narrow channel, but in this case, the fissure was covered with crumbling soil. Thus, in the modeling, the approach treated this area by assigning a material with the greater saturated hydraulic conductivity than the surrounding. Therefore, in the modeling, two kinds of material were used and set, as shown in Fig 5. The soil water dynamics closely relate to the soil temperature regime [33]. However, in this simulation, the effects of atmosphere and temperature were not considered.

The observation was conducted for the different levels of water table, which are $10 \mathrm{~cm}, 15 \mathrm{~cm}, 20 \mathrm{~cm}, 25 \mathrm{~cm}$, and $30 \mathrm{~cm}$ from the soil base. One level was set after the lower level had been set for $24 \mathrm{hrs}$. This was also to imitate the observation, which used different water table levels setting (setpoint). The initial conditions for each water table level's simulation followed the previous simulation step.

\section{Results and Discussion}

\subsection{Performance of automated irrigation system}

In this study, the water table variation was set up by giving the corresponding pressure head in the form of water level in the reservoir that was controlled automatically. Then, the system autonomously turned on and off the solenoid valve to irrigate or stop the flow of subsurface irrigation water to maintain the water table. One automatic operation cycle included reading water level sensor data, processing data, activating/deactivating valves, sending data to the server, and retrieving setting data from the server; in this case, we called this cycle as an event. The observation of the automatic irrigation system's performance was done by analyzing events that were successfully recorded by the server and did not experience any interruptions in the data transmission process.

Figure 6 shows the water level variation during irrigation operation. Upper and lower setpoints were set according to irrigation needs, in a large or narrow range, and brought to zero to set inactive. The water table was expected to fluctuate between upper and lower setpoints; however, the water table sometimes exceeded the upper setpoint. Irrigation activity is represented by bars from the top of the chart; its appearance means the control system responding to the requirement to increase the water table. Based on the event received by the server, the system's success rate in maintaining the water level was analyzed as $90 \%$ of the total 17046 events and had an RMSE error control of $0.86 \mathrm{~cm}$, indicating that the system was reliable in providing water table at a certain level in the soil.

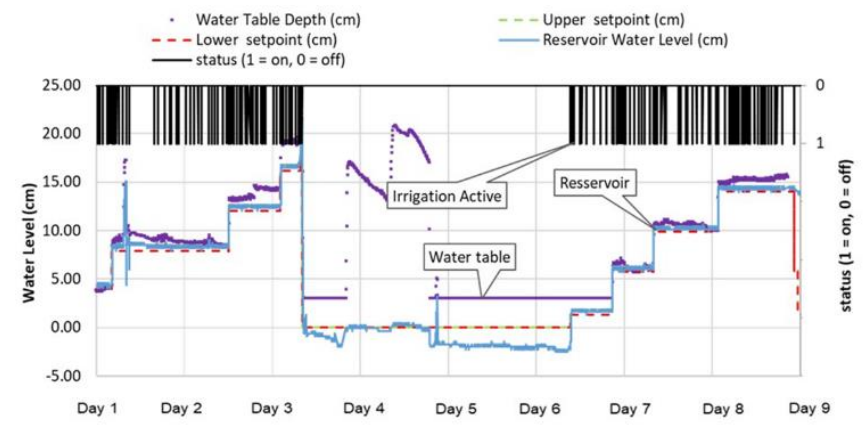

Fig. 6 Irrigation activity, controlled water levels and water table at the reservoir, over the sheet pipe, and center of the soil, $0 \mathrm{~cm}$ equals $Z=15 \mathrm{~cm} ; 25$ $\mathrm{cm}$ is the top of soil $(\mathrm{z}=40 \mathrm{~cm})$

The development of IoT and intelligent systems in subsurface irrigation is currently being researched, such as by [34]. Platforms for similar technology have been developed by $[35,36]$ or, in this paper, developed with local partners. The challenge was how this kind of technology could be used at the farm level, as presented by [37]. Thus, this should be 
considered a continuation of this study, aside from the appropriate irrigation technique and performance analysis.

\subsection{Response of water table and soil moisture to the water level in the reservoir}

In all this part of the study, we focused on observations started from Day 6, with the water level setpoints of approximately $6 \mathrm{~cm}, 10 \mathrm{~cm}$, and $14 \mathrm{~cm}$. The water table observed directly in the soil showed the response to the water level set in the reservoir. Observation results are depicted in figure 7, showing the measurement of the water table compared to the water level in the reservoir. In addition, soil moisture distribution above the water table resulting from automatic irrigation control was observed.

Water content measured between pipelines showed an increase when the water table was increased closer to the measurement point at ground level. This was caused by a capillary rise from the saturated layer of water closer to the soil surface. Capillary rise is the upward flow of water in the soil above the saturation zone $[38,39]$ and plays a relevant role in water availability near the surface due to the presence of capillary forces in the pores of the unsaturated soil above the water table [40]. Based on the soil moisture sensor data used, it can be concluded that the water content on the surface tends to increase with irrigation operations at higher water table setpoints. By the end of observation, soil water content values were in the range of available water to near saturation.

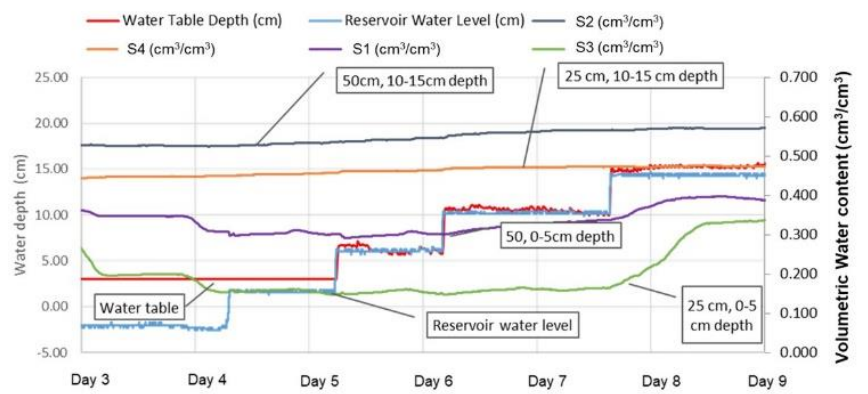

Fig. 7 Water level, water table, soil moisture, $0 \mathrm{~cm}$ equals $\mathrm{Z}=15 \mathrm{~cm} ; 25 \mathrm{~cm}$ is the top of the soil $(\mathrm{z}=40 \mathrm{~cm})$

\subsection{Numerical simulation}

The simulation was conducted with the staging level of setpoints. The water table was set at $10 \mathrm{~cm}, 15 \mathrm{~cm}, 20 \mathrm{~cm}, 25 \mathrm{~cm}$, and $30 \mathrm{~cm}$ from the soil base for simplification. These values were given as boundary conditions at the top of the pipe (height $Z=15 \mathrm{~cm}$ soil base) with the variable heads of $-5 \mathrm{~cm}, 0 \mathrm{~cm}, 5 \mathrm{~cm}$, $10 \mathrm{~cm}$, and $15 \mathrm{~cm}$. Each setpoint was applied for approximately $24 \mathrm{hrs}$ so that the variable head was set for the same range 0$24 \mathrm{hrs}$.

The relationship between experimental soil water content and soil potential is represented by equation (2), with parameter values enlisted in Table 1 as Soil I. The other two sets of parameters are also enlisted in the table and used for additional simulation representing different Ks. The model curve and soil potential data of the experimental soil are shown in Fig. 8.

There were two materials used in the simulation, first was the soil media whose properties were described previously. The second material was sand from the software's database to represent material that filled the fissure above the mole drain pipe, which in reality is filled with crumbled soil media but with probably higher permeability, which is not easily determined. Simulations were also carried out with other two soil types, i.e. Soil II and Soil III, with different permeability, as presented in Table 1 .

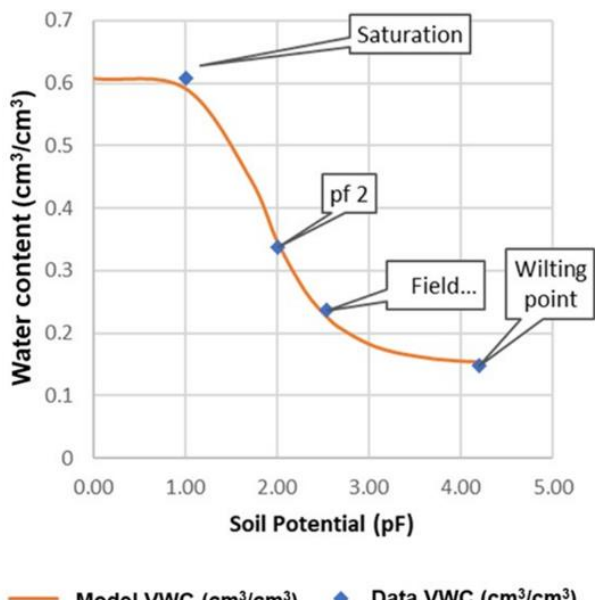

Fig. 8 Soil water retention curve

Table 1 Soil hydraulics parameters

\begin{tabular}{lccc}
\hline \multicolumn{1}{c}{ Parameter } & Soil I & Soil II * & Soil III* \\
\hline $\mathrm{qs}\left(\mathrm{cm}^{3} / \mathrm{cm}^{3}\right)$ & 0.608 & 0.410 & 0.430 \\
$\mathrm{qr}\left(\mathrm{cm}^{3} / \mathrm{cm}^{3}\right)$ & 0.150 & 0.057 & 0.045 \\
$\alpha$ & 0.026 & 0.124 & 0.145 \\
$\mathrm{n}$ & 1.816 & 2.280 & 2.680 \\
$\mathrm{Ks}(\mathrm{cm} / \mathrm{hr})$ & 5.000 & 14.592 & 29.700 \\
$\mathrm{~m}$ & 0.449 & 0.561 & 0.627 \\
\hline
\end{tabular}

* These values were adopted from From [41]

An example of the simulation results is shown in Fig. 9, namely water content, pressure head, and flow vector for 25 hours simulation with variable head $=0 \mathrm{~cm}(Z=15 \mathrm{~cm})$ at the mole-drain pipe. The water content in the sand material was found lower than the surrounding, while at the pipe level to the bottom of the soil it was in water saturation. Meanwhile, the pressure on the sand material was higher than in the surrounding media. When irrigation water flowed into the pipe, with pressure equal to the water level in the reservoir, a stream of water flowed out from the top of the pipe. Water continued to flow from the top and wetting the soil, as shown by the flow velocity vector in Fig. 9.
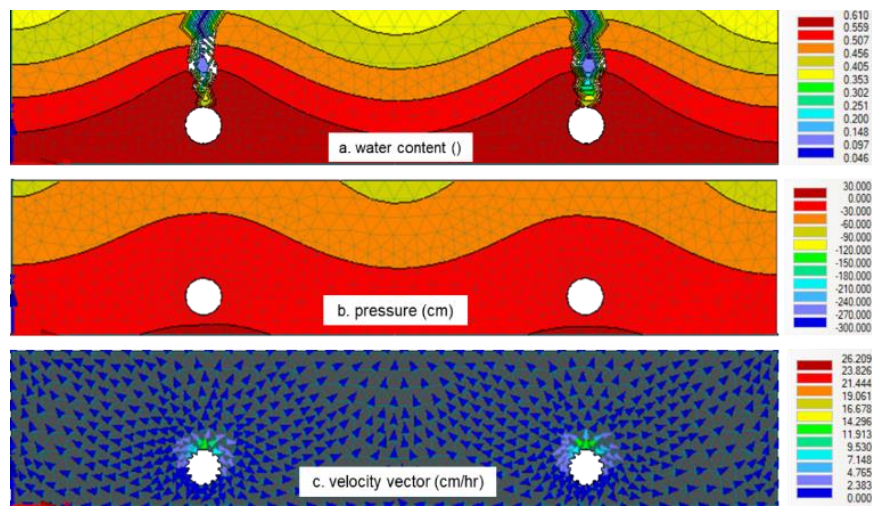

Fig. 9 Graphic presentation of 2-dimensional numerical simulation of subsurface irrigation at a setpoint of $15 \mathrm{~cm}$ (head $=0 \mathrm{~cm})$, simulation time $\mathrm{t}=$ $25 \mathrm{hrs}$ : a. distribution of water content $\left(\mathrm{cm}^{3} / \mathrm{cm}^{3}\right)$, b. distribution of pressure head $(\mathrm{cm})$, c. flow velocity vector $(\mathrm{cm} / \mathrm{hr})$ 
The simulation was carried out by setting the initial soil surface conditions at a pressure head of $-300 \mathrm{~cm}$, and the soil base was $0 \mathrm{~cm} \mathrm{H}_{2} \mathrm{O}$, linearly distributed with depth. For observations, 4 points were placed at a distance of $50 \mathrm{~cm}$ and $25 \mathrm{~cm}$ from the pipe with $\mathrm{z}=30 \mathrm{~cm}$ and $\mathrm{z}=40 \mathrm{~cm}$. In addition, the observations of vertical profiles were also carried out by placing the cross-sections in the middle of the model. The water content and pressure head were observed at the center of the simulation model are presented in Fig. 10.

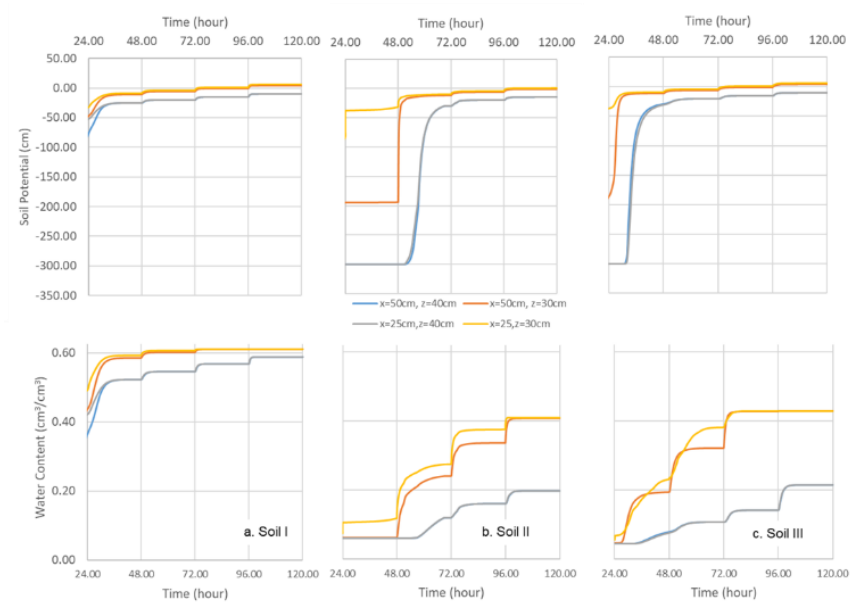

Fig. 10 Numerical simulation results of 2 dimensions of automatic irrigation at setpoints: $10 \mathrm{~cm}, 15 \mathrm{~cm}, 20 \mathrm{~cm}, 25 \mathrm{~cm}$, and $30 \mathrm{~cm}$ for Soil I (left), Soil II (middle), and Soil III (right); presented in pressure head (top) and water content (bottom). Observed at the $50 \mathrm{~cm}$ and $25 \mathrm{~cm}$ between sub-irrigation pipelines at height $30 \mathrm{~cm}$ and 40 above the base

The increase in soil potential and soil water content of Soil I can be seen in Fig. 10, gradually following the setpoint level change, represented by the variable head boundary condition. The soil at $\mathrm{z}=30 \mathrm{~cm}$ was wetter than at the surface $(\mathrm{z}=40 \mathrm{~cm})$ because it was closer to the water table. The flow of water to the point at a distance of $50 \mathrm{~cm}$ took longer, thus causing the soil conditions to be relatively drier at a distance of $25 \mathrm{~cm}$ from the pipeline.

The soil at $\mathrm{z}=30 \mathrm{~cm}$ reached the saturation point at the end of the simulation, indicated by the potential soil value above $0 \mathrm{~cm}$ and the water content reaching $0.6 \mathrm{~cm}^{3} / \mathrm{cm}^{3}$. This condition was confirmed by the water content measured in the center of the model at a depth of $10 \mathrm{~cm}-15 \mathrm{~cm}$ from the surface during observation. Meanwhile, the saturation condition was not reached at ground level, still under the conditions expected in this water table control.

The wetting in Soil II and Soil III appeared to be different from Soil I. In both, there was a larger gap between the level of wetness at $\mathrm{z}=30 \mathrm{~cm}$ and the surface, at a distance of $50 \mathrm{~cm}$ and $25 \mathrm{~cm}$ from the pipeline compared to Soil I. Therefore, the achievement of soil saturation at the water table level in the middle occurred more slowly. These wetting patterns might show that the use of a variable head boundary condition equal to water level in a reservoir connected to the subsurface sheet pipe system can perform as expected.

\subsection{Discussion}

As shown in Fig. 6, the automatic system works to retrieve data from the water table sensor and compare it with the predetermined water table setpoint. If the water level in the reservoir is lower than the setpoint, the irrigation valve will open to flow water into the model. Irrigation water will enter through the sheet pipe below the surface and fill the soil pores around and above it until there is a balance of water pressure in the model (water level) and in the reservoir where water regulation is carried out. Because the filling of water in the soil is not as fast as filling the reservoir, the irrigation will flow again when the system detects that the water level in the reservoir is falling due to the flow of water filling the water into the soil pores. This system does not yet have an automatic drainage system, and the water level can increase when it rains, but if this does not happen, it can be seen that the system has been able to work and maintain the water table according to various sets points.

The simulation results showed that during the irrigation, soil moisture at the surface was drier than beneath and seemed to be very little flux of water at the layer near the surface. This condition agreed with $[42,43]$ that volumetric water content remained relatively high around the root zone in an experiment of subsurface irrigation, while at the soil surface it was very low and nearly constant, and loss through soil evaporation can be reduced. This showed that the simulated sub-surface irrigation with a controlled water table with sheet pipe can perform as expected in general subsurface irrigation.

The soil moisture above the water table, which could be maintained during the experiment, showed an increase due to the capillary rise, causing the wetting of the soil above it. This showed that soil moisture can be supplied with a certain level of wetness by setting the water table. This level of wetness affected the ease with which water could be taken up by plant roots, as represented by the soil potential, where the higher value, for example, from negative to close to zero, indicated that water was more available for absorption roots. So it is essential to know the distribution of this moisture distribution in the soil by measuring, analyzing the soil's physical properties, and stimulating the flow of water in the soil. Observations and simulations showed the set point of the water table by providing a varying heads at the subsurface irrigation outlet hole according to the water level in the reservoir, which can supply moisture above it.

When the setpoint was changed to a higher water table, soil wetting occurred in the upper layer. This wetting took place gradually and stopped when the soil layer at the setpoint height was saturated with water, indicated by the soil potential value approaching zero. This is a condition where the water table has reached the desired height. The process occurs when the setpoint is set higher, and irrigation water enters and supplies water to the soil.

A similar case for subsurface irrigation to this method was carried out by [17], who placed a porous pipe over a trapezoidal or rectangular barrier, applying different depths. The difference was that the barrier in the sheet-pipe subsurface irrigation system was a mole drain with a cylindrical cross-section with an opening at the top. This condition caused the water flow flux to occur only from the top of the pipe with a surface area not as large as a trapezoidal or rectangular barrier. However, as the sheet-pipe system was developed initially for drainage, the structural design of the mole drain barrier was given. Thus, instead, both automatic irrigation and drainage could be provided by the same system.

Subsurface irrigation is generally developed to increase water use efficiency by reducing losses through evaporation while maintaining the water supply in plant roots according to needs such as Optimized Subsurface Irrigation System (OPSIS) for sugar cane presented by $[44,45]$. Like the technique presented in this paper, OPSIS was also automatically operated by solar power or designed to operate as long as solar energy was available in the daytime, which is perfect for dry land water management. OPSIS also used a barrier beneath the perforated 
pipe [17] that reduced losses by percolation. In the Rainy season, this kind of installation can serve as a drainage system.

The technique was based on sheet pipe technology initially developed to overcome waterlogging on land, thus more suitable for use in lowland, facing inundation in the rainy season, and water table drop in the dry season. So if a system that can adjust the water table properly is available, it can help agricultural or other activities on the land surface. Therefore, it would be more effective if further developed to control the water table as in [46-48]. A further application is suggested to lowland areas that suffer from challenging water management problems. The selection of this method can consider other things, for instance wetlands that may be used for agricultural production while maintaining the water table near the surface.

Irrigation applications can be aimed at providing suitable soil moisture in the root area. To increase irrigation efficiency, water can be applied according to the targeted soil moisture; for example, with soil moisture ignited, automatic subsurface drip irrigation proposed by [49]. Providing the appropriate soil moisture in the root area by maintaining a water table suitable for cultivation, soil conditions, and seasons is also a challenge for further study and development of this technique. The research presented by $[47,48]$ can be a reference for further studies and planning water table control for agriculture.

The improvement of the model should be considered for future work as the numerical model could not accurately imitate the advancement of the water table at the setpoint level. One of the causes was probably related to the use of boundary condition of the variable head only at one point at the outlet of the pipe. In reality, water suddenly rises within the fissure and forms a nonnegative headline rather than a point.

Numerical modeling and simulation with HYDRUS can greatly represent the water flow process in the soil in a subsurface drip irrigation application [22]. The distribution of soil moisture from irrigation emitter points can be estimated quite accurately based on the statistical analysis presented. The steps in the experiment in [22] need to be carried out to improve this study both in the laboratory and in the field for subsurface irrigation, which focuses on water table. A more comprehensive study on subsurface irrigation is presented by [50]. The laboratory-scale model observation presented in this paper should be followed by field scale observation to enrich information regarding sheet pipe sub-surface technology that has not been covered in previous studies. Various aspects and approaches are presented in this study, some of which are subsurface irrigation perforated pipe, automation, water sensor usage and numerical investigation using HYDRUS. This thesis can be a reference for the author in continuing this study, as well as the readers.

This study is limited to experiments using a laboratory-scale and numerical model to imitate laboratory-scale models, aiming to observe the automated subsurface irrigation system's performance. One focus is on setting the water table and its effect on the distribution of soil moisture, soil potential, and flux. Field-scale research and experiments with planting will be planned for the next stage.

\section{Conclusion}

Subsurface automatic irrigation systems with sheet pipes can work well in providing a certain level water table according to a specified setpoint. The water table maintained during the experiment can provide soil moisture to the upper layer of the soil. The developed two-dimensional numerical simulation showed the distribution of soil moisture in the center of the model as a response to the increase of water table, represented by variable head. The soil wetting advanced toward soil surface driven by the water table, increased gradually and reached saturation at the height of water table setpoint.

The simulation model still needs to be improved to approach the actual condition by adjusting the boundary conditions or hydraulic conductivity. This research could only provide limited information about subsurface irrigation techniques with sheet pipes, including the scope of experiments, observations, and the accuracy of numerical models to reality. More extensive and intensive studies are required then, such as experiments and modeling for the field scale, within a growing season or long term.

\section{Acknowledgments}

According to the contract, this research was funded by the Ministry of Education, Culture, Research, and Technology under a research project titled "Development of Eco-friendly Paddy Field Water Management System with Sheet pipe Sub-surface Drainage Technology" according to contract and sub-contract number: 1/E1/KP.PTNBH/2021 and 2097/IT3.L1/PN/2021. The authors would like to thank Kyouwa Kensetsu Kougyou LTD and PT Meteo Nusantara Instrument for providing technology and technical support during the research as well as to the Directorate General of Higher Education, Ministry of Education and Culture, the Republic of Indonesia for all their support on this study

\section{References}

1. Y. M. Soe, Y. Shinogi, and T. Taniguchi, Impacts of perforated sheet pipe installation on some paddy soil properties, Paddy Water Environ., 2019.

2. H. Matsuda, K. Tamura, B. Setiawan, and S. Saptomo, Effects of drainage by the sheet pipe on the suction and volume water content of subsurface layer, 2019.

3. B. I. Setiawan, SK. Saptomo, C. Arif, AA. Sulaiman, S. Herodian, H.Matsuda et al., Waterflow in the Paddy Field Installed with Sheetpipe Mole Drains, 2019.

4. C. Arif, B.I. Setiawan, S.K. Saptomo, H. Matsuda, K. Tamura, Y. Inoue et al., Performances of sheet-pipe typed subsurface drainage on land and water productivity of paddy fields in Indonesia, Water (Switzerland), 13 (2021) 1-13.

5. P. Sasmita, N. Agustiani, S. Margaret, A. M. Yusup, and K. Tamura, The effect of sheet-pipe technology aplication on soil properties, rice growth, yield and prospect to increase planting index, in IOP Conference Series: Earth and Environmental Science, 648 (2021) 1-9.

6. A. Mulyani, D. Nursyamsi, and M. Syakir, Strategies for utilizing land resources to achieve sustainable self sufficiency on rice, J. L. Resour., 11 (2017) 11-22.

7. Ar-Riza and Alkasuma, Pertanian lahan rawa pasang surut dan strategi pengembangannya dalam era otonomi daerah (tidal swamp farming and its development strategy in the era of regional autonomy) (in Indonesian), J. Sumberd. Lahan, 2 (2008) 95-104.

8. B. P. Statistik, Statistik Indonesia tahun 2016 (Indonesian statistics 2016) (in Indonesian). Jakarta: Badan Pusat Statistik, 2016.

9. S. Fukai and M. Ouk, Increased productivity of rainfed lowland rice cropping systems of the Mekong region, Crop and Pasture Science, 63 (2012) 944-973.

10. K. Watanabe, Improvement in rainfed rice production during an era of rapid national economic growth: A case study of a village in Northeast Thailand, Southeast Asian Stud., 6 (2017) 293-306.

11. H. M. Ediarmanto, A. B. M. Arshad, E. Wildayana, and M. S. Imanudin, Land evaluation for paddy cultivation in the reclaimed tidal lowland in Delta Saleh, South Sumatra, Indonesia, J. Sustain. Sci. Manag., 8 (2013) 32-42.

12. M. S. Imanudin, E. Armanto, R. H. Susanto, and S. M. Bernas, Water table Fluctuation in tidal lowland for developing agricultural water 
management strategies, J. TANAH Trop. (Journal Trop. Soils), 15 (2010) 277-282.

13. M. S. Imanudin, E. Armanto, R. H. Susanto, and S. M. Bernas, The study water table fluctuation in tidal lowland for developing agricultural water management strategies: (A case study for corn cultivation after rice), 2010.

14. N. L. Powell and F. S. Wright, Grain yield of subsurface microirrigated corn as affected by irrigation line spacing, Agron. J., 85 (1993) 1164 1169

15. B. R. Hanson, L. J. Schwankl, K. F. Schulbach, and G. S. Pettygrove, A comparison of furrow, surface drip, and subsurface drip irrigation on lettuce yield and applied water, Agric. Water Manag., 33 (1997) 139-157.

16. C. R. Camp, Subsurface drip irrigation: A review, Transactions of the American Society of Agricultural Engineers, 41 (1998) 1353-1367.

17. A. Sakaguchi, Y. Yanai, and H. Sasaki, Subsurface irrigation system design for vegetable production using HYDRUS-2D, Agric. Water Manag., 219 (2019) 12-18.

18. T. H. Skaggs, T. J. Trout, and Y. Rothfuss, Drip irrigation water distribution patterns: effects of emitter rate, pulsing, and antecedent water, Soil Sci. Soc. Am. J., 74 (2010) 1886-1896.

19. S. Dabach, N. Lazarovitch, J. Šimůnek, and U. Shani, Numerical investigation of irrigation scheduling based on soil water status, Irrig. Sci., 31 (2013) 27-36.

20. M. N. El-Nesr, A. A. Alazba, and J. Šimůnek, HYDRUS simulations of the effects of dual-drip subsurface irrigation and a physical barrier on water movement and solute transport in soils, Irrig. Sci., 32 (2014) 111-125.

21. T. H. Skaggs, T. J. Trout, J. Šimůnek, and P. J. Shouse, Comparison of HYDRUS-2D simulations of drip irrigation with experimental observations, J. Irrig. Drain. Eng., 130 (2004) 304-310.

22. M. M. Kandelous and J. Šimůnek, Numerical simulations of water movement in a subsurface drip irrigation system under field and laboratory conditions using HYDRUS-2D, Agric. Water Manag., 97 (2010) 1070-1076.

23. M. M. Kandelous, J. Šimůnek, M. T. van Genuchten, and K. Malek, Soil water content distributions between two emitters of a subsurface drip irrigation system, Soil Sci. Soc. Am. J., 75 (2011) 488-497.

24. R. Saefuddin, H. Saito, and J. Šimůnek, Experimental and numerical evaluation of a ring-shaped emitter for subsurface irrigation, Agric. Water Manag., 2019 111-122.

25. J. Šimůnek, M. T. van Genuchten, and M. Šejna, Recent developments and applications of the HYDRUS computer software packages, Vadose Zo. J., 2016 1-25.

26. D. E. Radcliffe and J. Šimůnek, Soil physics with HYDRUS: Modeling and applications. 2010.

27. B. I. Setiawan et al., Automatic subsurface irrigation and drainage using sheet-pipe typed mole drain., 2019.

28. S. K. Saptomo et al., Development of laboratory scale model of field automatic water control system with sheetpipe technology, IOP Conf. Ser. Earth Environ. Sci., 871 (2021) 1-8.

29. P. Leeds-Harrison, G. Spoor, and R. J. Godwin, Water flow to mole drains, J. Agric. Eng. Res., 27 (1982) 81-91.

30. J. Šimůnek, M. T. Van Genuchten, and M. Šejna, The HYDRUS software package for simulating the two-and three-dimensional movement of water, heat, and multiple solutes in variably-saturated porous media, Tech. manual, version, 2 (2012) 1-213.

31. M. T. van Genuchten, A Closed-form equation for predicting the hydraulic conductivity of unsaturated soils, Soil Sci. Soc. Am. J., 44 (1980) 892898.

32. Y. Mualem, A new model for predicting the hydraulic conductivity of unsaturated porous media, Water Resour. Res., 1976.

33. H. Saito, J. Šimůnek, and B. P. Mohanty, Numerical analysis of coupled water, vapor, and heat transport in the vadose zone, Vadose Zo. J., 2 (2006) 784-800.

34. M. Mohammed, K. Riad, and N. Alqahtani, Efficient iot-based control for a smart subsurface irrigation system to enhance irrigation management of date palm, Sensors, 21 (2021) 1-28.

35. C. Kamienski et al., Smart water management platform: IoT-based precision irrigation for agriculture, Sensors (Switzerland), 2019.

36. R. Ullah et al., EEWMP: An IoT-Based energy-efficient water management platform for smart irrigation, Sci. Program., 2021 (2021) 19.

37. E. Nigussie, T. Olwal, G. Musumba, T. Tegegne, A. Lemma, and F. Mekuria, IoT-based irrigation management for smallholder farmers in rural Sub-Saharan Africa, in Procedia Computer Science, 177 (2020) 8693.

38. J. Bear, Hydraulics of groundwater., 1979.

39. D. Hillel, Environmental Soil Physics. New York: Academic Press, 1998.

40. Jury, W. A., W. R. Gardner, and W. H. Gardner, Soil Physics, 5th ed. New York.: John Wiley, 1991.

41. R. F. Carsel and R. S. Parrish, Developing joint probability distributions of soil water retention characteristics, Water Resour. Res., 24 (1988) 755769.

42. K. Yuge, K. Hamada, M. Anan, A. Hirakawa, and Y. Shinogi, Evaluation of soil water movement under subsurface irrigation in dark-red clay soil fields in Okinawa, J. Clay Sci. Soc. Japan (in Japanese), 52 (2014) 123128.

43. K. Hamada, K. Yuge, M. Anan, A. Hirakawa, and Y. Shinogi, Evaluation of the water saving effect of subsurface irrigation in shimajiri mahji soil fields, J. Food, Agric. Environ., 13 (2015) 54-59.

44. M. H. J. P. Gunarathna et al., Optimized subsurface irrigation system: The future of sugarcane irrigation, Water (Switzerland), 10 (2018) 1-14.

45. M. H. J. P. Gunarathna et al., Optimized subsurface irrigation system (OPSIS): Beyond traditional subsurface irrigation, Water (Switzerland), 9 (2017)1-11.

46. C. Arif, M. I. Fauzan, K. S. Satyanto, I. S. Budi, and M. Masaru, Developing automatic water table control system for reducing greenhouse gas emissions from paddy fields, 2018.

47. J. L. Fouss, R. W. Skaggs, and J. E. Ayars, Irrigation via watertable control, in ASAE Publication, 1990.

48. J. L. Fouss, R. O. Evans, J. E. Ayars, and E. W. Christen, Water table control systems, Des. Oper. Farm Irrig. Syst., (1991) 684-724.

49. M. D. Dukes and J. M. Scholberg, Soil moisture controlled subsurface drip irrigation on sandy soils, Appl. Eng. Agric., 21 (2005) 89-101.

50. P. B. CHARLESWORTH, Investigation of the efficiency and long term performance of various sub-surface irrigation configurations under field conditions, School of Agriculture Charles Sturt University New South Wales., 2003 